\title{
Association between the morphology and thickness of bony components of the temporomandibular joint and gender, age and remaining teeth on cone-beam CT images
}

\section{Związek pomiędzy morfologią i grubością części kostnych stawu skroniowo-żuchwowego a płcią, wiekiem oraz liczbą zachowanych zębów na postawie przekrojów tomografii stożkowej}

\author{
Tahmineh Razi ${ }^{A, D-F}$, Sedigheh Razi ${ }^{A-D}$ \\ Department of Oral and Maxillofacial Radiology, Faculty of Dentistry, Tabriz University of Medical Sciences, Iran \\ A - research concept and design; $\mathrm{B}$ - collection and/or assembly of data; $\mathrm{C}$ - data analysis and interpretation; \\ $D$ - writing the article; $E$ - critical revision of the article; $F$ - final approval of the article
}

Address for correspondence

Sedigheh Razi

E-mail: sed_razi@yahoo.com

Funding sources

None declared

Conflict of interest

None declared

Received on April 28, 2018

Reviewed on May 28, 2018

Accepted on July 24, 2018

DOI

$10.17219 / \mathrm{dmp} / 93727$

Copyright

○ 2018 by Wroclaw Medical University

and Polish Dental Society

This is an article distributed under the terms of the

Creative Commons Attribution Non-Commercial License

(http://creativecommons.org/licenses/by-nc-nd/4.0/)

\section{Abstract}

Background. Various factors such as aging, sex hormones and the distribution pattern of occlusal forces affect the morphology and osseous components of the temporomandibular joint (TMJ). Recognition of the effects of these factors on the anatomy of the area results in the differentiation of normal variations from abnormal cases.

Objectives. The aim of the present study was to evaluate the relationship between the condyle and other hard components of TMJ, and age, gender and the number of remaining teeth.

Material and methods. In the present descriptive-analytical study, a total of 145 cone-beam computed tomography (CBCT) images were evaluated. The condyle morphology, the thickness of the glenoid fossa roof, and the height and slope of the eminence were evaluated.

Results. There were significant differences between the right and left sides only in terms of the height of the articular eminence ( $p=0.008$ and $p \leq 0.001$ on the right and left side, respectively). There were significant differences between both sides in the slope of articular eminence depending on the number of teeth ( $p=0.01$ and $p=0.008$ on the right and left side, respectively). The height of the articular eminence on the left side differed significantly depending on age $(p=0.005)$ and the number of remaining teeth $(p=0.02)$. There were no significant differences in any other cases.

Conclusions. No significant relationship was found between the thickness of the glenoid fossa roof and the articular eminence, and the condyle morphology in all 3 cross-sections regarding gender, age and the number of remaining teeth.

Key words: cone-beam computed tomography, thickness of glenoid fossa, height of articular eminence, slope of articular eminence, condyle morphology

Słowa kluczowe: stożkowa tomografia komputerowa, grubość dołka stawowego, wysokość guzka stawowego, stok guzka stawowego, morfologia kłykcia 


\section{Introduction}

The temporomandibular joint (TMJ) is a center of growth and it is important for chewing since it bears the loads during mastication. ${ }^{1,2}$ It is a bilateral joint and has a unique function and morphology. ${ }^{3}$ The forces exerted on TMJ affect the osseous components of the joint, resulting in changes in the thickness and form of these components. These changes are considered beyond the scope of normal variations if excessive loads are exerted on the joint, necessitating the elimination of the etiologic agents. ${ }^{4-6}$

Cone-beam computed tomography (CBCT) provides the necessary information for the diagnosis of TMJ problems $^{7,8}$; however, it is less reliable in relation to the soft tissue contrast and the calcification of soft tissues. ${ }^{9}$ In one of the studies, $1 / 4$ (25\%) of initial diagnoses regarding termomandibular disorders (TMD) made by oral and maxillofacial surgeons after examination and evaluation of panoramic radiographs were corrected after CBCT examination and evaluation of $\mathrm{CBCT}$ images, resulting in a change in the treatment plan in $12 \%$ of cases. ${ }^{10}$

Morphologic changes due to the effects of sex hormones and metabolic activity during adulthood result in differences between males and females. ${ }^{11}$ In a study by Hedge et al., the prevalence of the convex shape of the condyle was higher in women. ${ }^{12}$ However, the results of the present study showed no differences between males and females in this respect. A study by Ejima et al. showed a lower frequency of the angular shape in the coronal view. ${ }^{13}$ A higher frequency of the flat shape was reported in women, with higher loads on the bones and joints being tolerated in men due to higher osseous density and thicker cortex. ${ }^{14}$

A large number of researchers believe that a higher slope of the articular eminence has an important role in disk displacement. ${ }^{15-19}$ One of the etiologic factors for degenerative changes in the joint is the internal derangement of the disk, which is more common in women. It is expected that, due to high prevalence of arthritic disturbances, the slope of the articular eminence is higher in females compared to males. There is controversy over the relationship between the articular slope and gender, and discrepancies have been reported in this context. The discrepancies between the results of different studies on TMJ might be attributed to differences in subject selection criteria, sample sizes and ethnicity.

The aim of the present study was to evaluate the morphology of the condyle and the thickness of other osseous components of TMJ on CBCT images in terms of age, gender and the number of remaining teeth.

\section{Material and methods}

A total of 145 patients referred to the Department of Oral and Maxillofacial Radiology, Faculty of Dentistry at Tabriz University of Medical Sciences (Iran) were included in this descriptive-analytical study in the years 2014-2015. The subjects, aged 20-80 years,

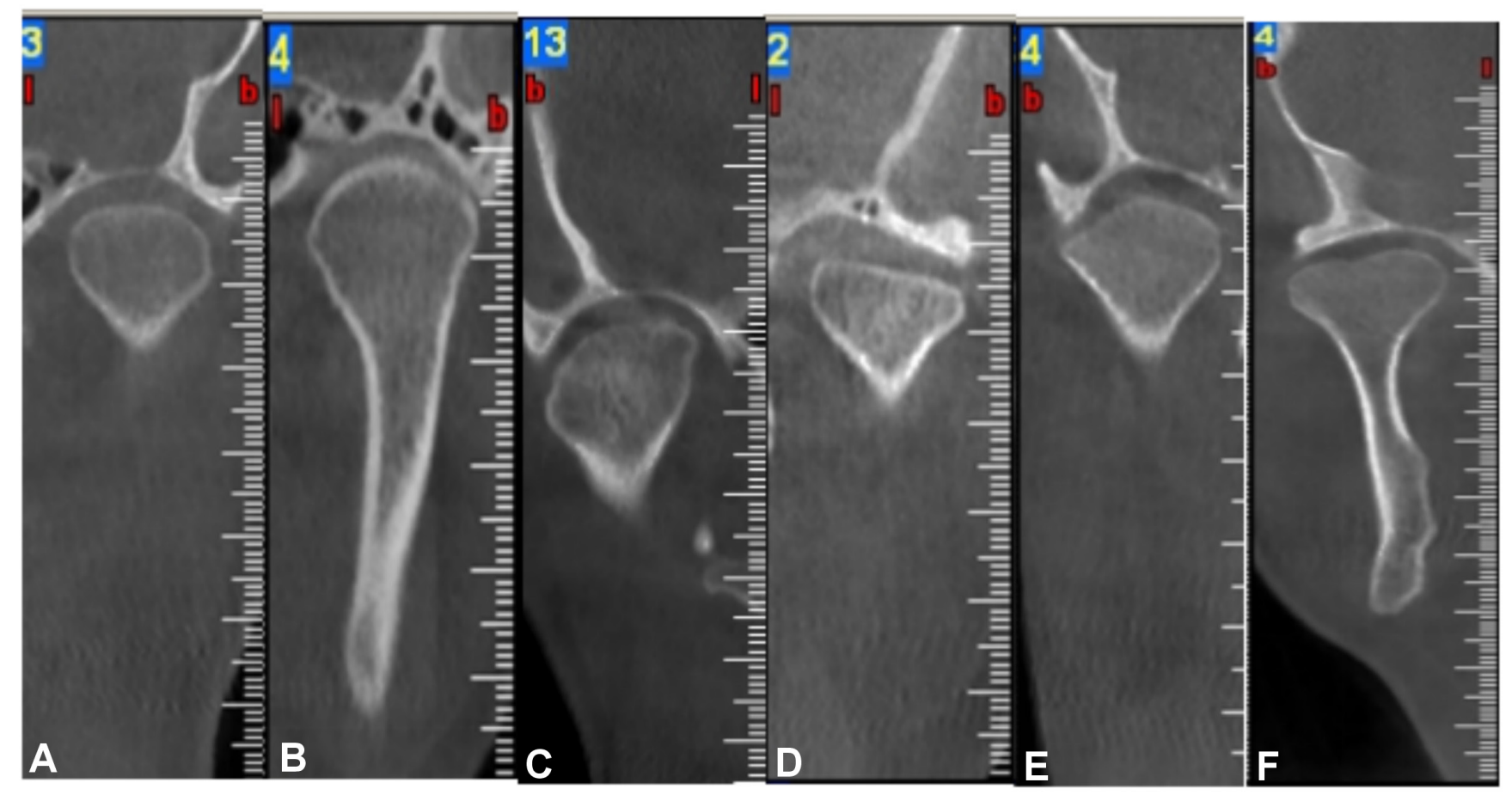

Fig. 1. Coronal morphology of the condyle ( $\mathrm{A}$ - convex; $\mathrm{B}$ - round; $\mathrm{C}$ - flat without any effect on the glenoid fossa; $\mathrm{D}$ - flat with an effect on the glenoid fossa; E - angled; F - heart-shaped) 
needed CBCT images for a variety of reasons. All radiographic examinations were carried out for other diagnostic purposes, such as implant placement. The inclusion criteria were as follows: no history of surgery, fracture or congenital defects of TMJ, no pathologic lesions in the jaws, and asymptomatic TMD. The exclusion criteria were as follows: faulty restorations with incorrect anatomical characteristics of occlusion, complete or partial prostheses, a history of systemic diseases, use of medications affecting the joints, a history of trauma, surgery or jaw lesions, or ill-fitting prostheses.

After obtaining informed consent, the age, gender and number of remaining teeth in the patients were recorded.

The CBCT images were taken with the use of a NewTom VGi ${ }^{\circledR}$ Cone-Beam CT unit (NewTom, Verona, Italy) in the Department of Oral and Maxillofacial Radiology. The CBCT unit used a conical X-ray beam, and was provided with a flat-panel detector, $1536 \times 1920$ pixels, $127 \mu \mathrm{m} \times 27 \mu \mathrm{m}$ pixel size, 14 -bit pixel depth, $360^{\circ}$ rotation, 18-second scan time, and peak kilovoltage $(\mathrm{kVp})=110$. The viewer software program v. 2.17 (NewTom) was used for initial and final reconstructions. The $\mathrm{X}$-ray conditions of the CBCT unit were adjusted automatically. The CBCT images prepared using the axial cross-sections were $0.5 \mathrm{~mm}$ in thickness. The sagittal cross-sections were evaluated perpendicular to the long axis of the condyle at a thickness of $1 \mathrm{~mm}$ and the coronal cross-sections were evaluated parallel to the long axis of the condyle at a thickness of $1 \mathrm{~mm}$.

Articular eminence measurements were made in the cross-sections, using the points and lines described, and the height of the eminence was calculated by measuring the vertical distance between the uppermost and lowermost points of the articular eminence. ${ }^{20}$

The morphology of the condyle was classified into 6 categories in coronal views: convex, round, flat with an effect on the glenoid fossa, flat without any effect on the glenoid fossa, angular, and heart-shaped (Fig. 1). This view was prepared at the widest medio-lateral cross-section of the condyle on the axial cross-section.

The morphology of the condyle was classified into 4 categories in the sagittal dimension: round, intermediate (a form between round and flat), flat without any effect on the glenoid fossa, and flat with an effect on the glenoid fossa (Fig. 2).

The condyle morphology was classified into 3 categories in the axial dimension: oval, bean-shaped and conical (Fig. 3).

The thickness of the glenoid fossa roof was measured in the sagittal view at its thinnest site.

The data was analyzed with descriptive statistical techniques, in addition to the t-test, $\chi^{2}$ test, correlation coefficient, univariate analysis of variance (ANOVA), and multivariate ANOVA, using SPSS v. 17 statistical software (IBM Corp., Armonk, USA). Statistical significance was set at $\mathrm{p}<0.05$.

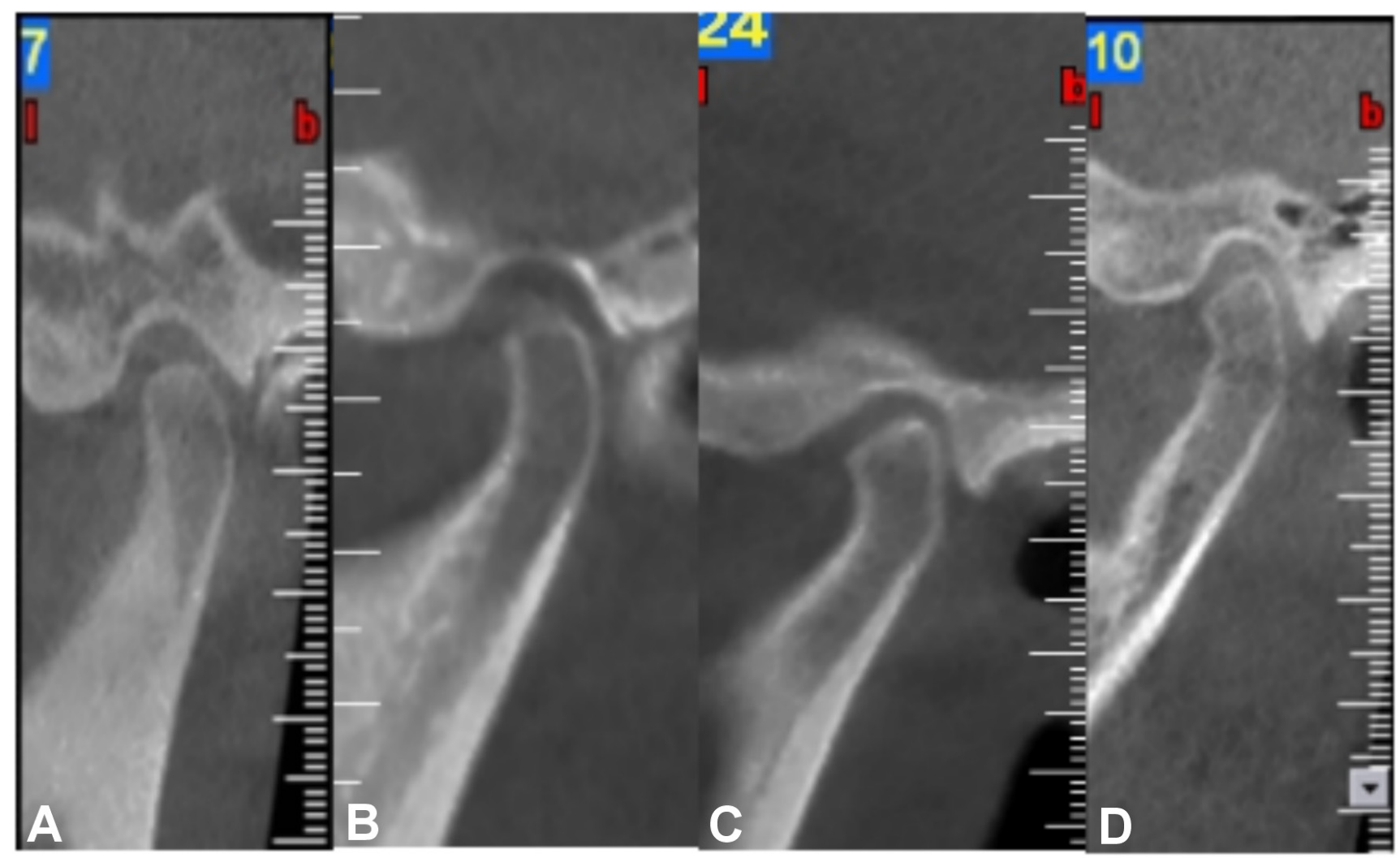

Fig. 2. Sagittal morphology of the condyle ( - round; B - intermediate; $C$ - flat with an effect on the glenoid fossa; D - flat without any effect on the glenoid fossa) 

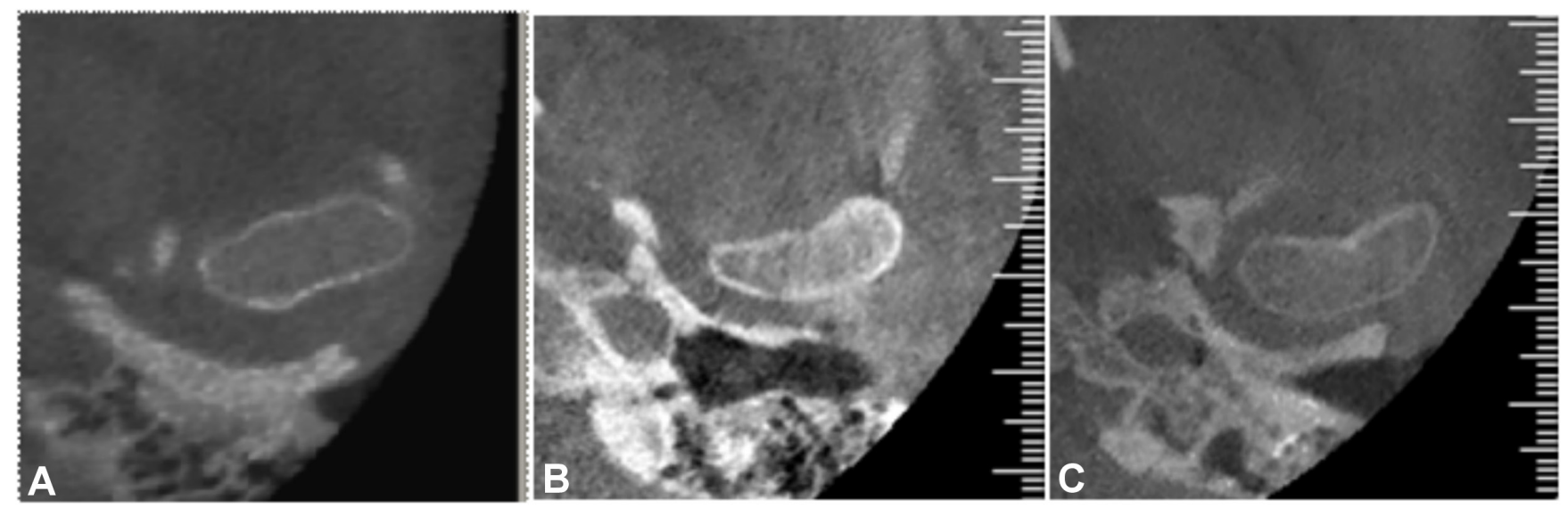

Fig. 3. Axial morphology of the condyle (A - oval; B - conical; C - bean-shaped)

\section{Results}

In the present study, 145 subjects with a mean age of $41.39 \pm 12.95$ years (age range: $20-80$ ) were evaluated, with 73 males $(50.30 \%)$ and 72 females $(49.70 \%)$.

There was no significant relationship between the condyle morphology and gender in the sagittal view on the right ( $\mathrm{p}=0.61)$ and left $(\mathrm{p}=0.99)$ sides, in the coronal view on the right $(\mathrm{p}=0.84)$ and left $(\mathrm{p}=0.46)$ sides, and in the axial view on the right $(\mathrm{p}=0.27)$ and left $(\mathrm{p}=0.82)$ sides. There was no significant relationship between the condyle morphology and age in the sagittal view on the right $(\mathrm{p}=0.49)$ side, in the coronal view on the right $(\mathrm{p}=0.12)$ and left $(\mathrm{p}=0.32)$ sides, and in the axial view on the right $(\mathrm{p}=0.85)$ and left $(\mathrm{p}=0.40)$ sides; however, there was a significant relationship between the condyle morphology and age in the sagittal view on the left side $(\mathrm{p}=0.04)$.

No significant relationships were shown between the condyle morphology and the number of remaining teeth in the sagittal view on the right $(\mathrm{p}=0.17)$ and left $(\mathrm{p}=0.41)$ sides, in the coronal view on the right $(\mathrm{p}=0.47)$ and left ( $\mathrm{p}=0.41)$ sides, and in the axial view on the right side $(\mathrm{p}=0.49)$; however, such a relationship was significant in the axial view on the left side $(\mathrm{p}=0.008)$.

The differences in the height of the articular eminence in terms of gender were significant on the right $(p=0.008)$ and left $(p \leq 0.001)$ sides. The difference in the slope of the articular eminence was significant on the right side $(\mathrm{p}=0.01)$, but it was not significant on the left side $(p=0.19)$. The relationships between the slope and height of the articular eminence and age and the number of remaining teeth are detailed in Table 1.

There was no significant relationship between the thickness of the glenoid fossa roof and gender on the left and right sides $(\mathrm{p}=0.12)$. The relationship between the thickness of the glenoid fossa roof and age is detailed in Table 2. The relationship between the thickness of the glenoid fossa roof and the articular eminence on one hand and the condyle morphology on the other hand was not significant in terms of gender, age and the number of remaining teeth in any of the cross-sections evaluated in the present study.

Table 1. Correlation between the slope and height of the articular eminence and the thickness of the glenoid fossa roof on both sides, and age and the number of remaining teeth

\begin{tabular}{|c|c|c|c|c|c|c|}
\hline Variable & $\begin{array}{l}\text { Slope of the right } \\
\text { articular eminence }\end{array}$ & $\begin{array}{c}\text { Slope of the left } \\
\text { articular eminence }\end{array}$ & $\begin{array}{l}\text { Height of the right } \\
\text { articular eminence }\end{array}$ & $\begin{array}{l}\text { Height of the left } \\
\text { articular eminence }\end{array}$ & $\begin{array}{l}\text { Thickness of the } \\
\text { right glenoid fossa }\end{array}$ & $\begin{array}{l}\text { Thickness of the } \\
\text { left glenoid fossa }\end{array}$ \\
\hline Age & $\begin{array}{l}p=0.15 \\
r=0.11 \\
n=145\end{array}$ & $\begin{array}{l}p=0.13 \\
r=0.11 \\
n=145\end{array}$ & $\begin{array}{l}p=0.10 \\
r=0.13 \\
n=145\end{array}$ & $\begin{array}{l}p=0.005 \\
r=0.23 \\
n=145\end{array}$ & $\begin{array}{l}p=0.14 \\
r=0.12 \\
n=145\end{array}$ & $\begin{array}{l}p=0.01 \\
r=0.28 \\
n=145\end{array}$ \\
\hline $\begin{array}{l}\text { Number } \\
\text { of remaining teeth }\end{array}$ & $\begin{array}{l}p=0.01 \\
r=0.20 \\
n=145\end{array}$ & $\begin{array}{l}p=0.008 \\
r=0.21 \\
n=145\end{array}$ & $\begin{array}{l}p=0.27 \\
r=0.09 \\
n=145\end{array}$ & $\begin{array}{l}p=0.02 \\
r=0.18 \\
n=145\end{array}$ & $\begin{array}{l}p=0.42 \\
r=0.06 \\
n=145\end{array}$ & $\begin{array}{l}p=0.07 \\
r=0.14 \\
n=145\end{array}$ \\
\hline
\end{tabular}

Table 2. Relationship between the thickness of the glenoid fossa roof and the articular eminence on one hand and condyle morphology on the other hand in terms of age

\begin{tabular}{|lccc|}
\multicolumn{1}{c}{ Variable } & p-value (sagittal view) & p-value (coronal view) & $p$-value (axial view) \\
\hline Thickness of the right glenoid fossa & 0.37 & 0.78 & 0.94 \\
Thickness of the left glenoid fossa & 0.52 & 0.51 & 0.35 \\
Height of the right articular eminence & 0.48 & 0.15 & 0.88 \\
Height of the left articular eminence & 0.10 & 0.89 & 0.84 \\
\hline
\end{tabular}




\section{Discussion}

The condyle and articular eminence morphology affect one another and are affected by other factors. ${ }^{21}$ A study by Zain-Alabdeen and Alsadhan showed the adaptation of the condyle to changes in the articular disk and articular eminence. ${ }^{22}$ However, another study reported absence of any effect of the condyle morphology and the number of remaining teeth on the thickness of the glenoid fossa in asymptomatic European patients. ${ }^{13}$ A systematic review showed that functional forces exerted on TMJ were different in males and females, and caused morphologic changes in both genders. The shape of the condyle and the glenoid fossa affect one another. ${ }^{12}$ Sümbüllü et al. observed that despite the greater height and slope of the articular eminence in males compared to females, no significant differences were found between the 2 groups. ${ }^{20}$ However, this study proved a significant difference in terms of age in the control group. ${ }^{20}$ A study by İlgüy et al. showed no relationship between the thickness of the glenoid fossa roof and gender. ${ }^{23}$

In the present study, no significant relationship was detected between gender and the joint shape in the axial view, with the oval shape being the most frequent on both sides in the axial view. Two cases of bilateral bifid joints were found.

One of the factors affecting changes in the morphology of the condyle is age; such changes have been recorded in the elderly due to degenerative processes in the joint. ${ }^{12}$ Morphologic evaluation of the condyle in terms of age in different cross-sections on both sides did not reveal any significant differences except for the left side in the sagittal cross-section. The significance of the results on the left side was attributed to the effect of higher prevalence of the intermediate shape at young ages on statistical analyses. In the present study, there was no relationship between the number of remaining teeth and the condyle morphology, which was consistent with the results of a study by Ejima et al. ${ }^{13}$

The height of the articular eminence was greater in males compared to females on both sides, in accordance with a large number of previous studies. Such greater height in men is rational given the higher bone mass and body height in men compared to women.

There are discrepancies in the results of studies regarding the relationship between age and the height of the articular eminence. ${ }^{20,23-26}$ In the present study, a decrease was shown in the height of the articular eminence along with age on the left side and a direct relationship was found between the height of the articular eminence on the left and the number of remaining teeth, i.e., the height of the articular eminence decreased with aging and a decrease in the number of remaining teeth.

It is expected that, due to greater prevalence of degenerative joint disease (DJD) in females, the slope of the articular eminence must be higher in females, ${ }^{6}$ but it is not possible to confirm the hypothesis that a high slope of the articular eminence is a predisposing factor for irreversible disk displacement. ${ }^{26}$ Some studies reported the opposite, as well as a higher slope in males. Such a discrepancy might be attributed to differences in the criteria used to select subjects. ${ }^{20,23}$ In the present study, the slope of the articular eminence in males was generally greater than that in females and a significant difference was found on the right side. Another study did not show a difference in the slope of the articular eminence between asymptomatic subjects and those with TMJ disorders. ${ }^{27}$

In the present study, age had no effect on the slope of the articular eminence on both sides. Some other studies did not report any effect of age on the slope of the articular eminence. ${ }^{20,23,28}$ In the present study, the slope of the articular eminence on both sides was under the influence of the remaining teeth, i.e., there was a direct relationship between them; the slope increased along with an increase in the number of remaining teeth.

In a study by Ejima et al., the thickness of the glenoid fossa roof was not influenced by age or the number of teeth lost. ${ }^{13}$ It was reported that the shape of the condyle and the thickness of the glenoid fossa roof were not affected by malocclusion, even in individuals who had lost a large number of teeth. Kijima et al. evaluated the effect of age on the thickness of the glenoid fossa roof and reported similar results. ${ }^{29}$ Despite a small sample size in those 2 studies, the results are consistent with those of the present study in respect to the relationship between age and the thickness of the glenoid fossa roof, except for the left side. The results of a study by İlgüy et al., similar to the present one, showed no relationship between the thickness of the glenoid fossa roof and gender. ${ }^{23}$

There is a significant relationship between the thickness of the glenoid fossa roof and the morphologic characteristics of the condyle in the sagittal view. ${ }^{13,30,31}$ Honda et al. reported a relationship between the thickness of the glenoid fossa roof and the internal derangement of the joint and osteoarthritis. ${ }^{32}$

Similar to the present study, İlgüy et al. reported no relationship between the number of remaining teeth and the thickness of the glenoid fossa roof. ${ }^{23}$

Several studies evaluated the relationship between the thickness of the glenoid fossa and the morphology of the condyle. Kijima et al. and Ejima et al. did not find a significant relationship between the thickness of the glenoid fossa roof and the condyle morphology in the coronal crosssection in patients with TMJ disorders, ${ }^{13,29}$ except that Ejima et al. evaluated asymptomatic subjects and pointed out that it was possible for joint disorder to have existed in their samples. ${ }^{13}$ The same authors reported a significant relationship between the thickness of the glenoid fossa roof and the condyle morphology, ${ }^{13}$ in accord with the results reported by Tsuruta et al..$^{30}$ The studies carried out in this subject did not evaluate the effects of age, gender and the remaining teeth. 


\section{Conclusions}

No significant relationship was found between the thickness of the glenoid fossa roof and the articular eminence on one hand and the condyle morphology on the other hand in all 3 cross-sections of the study in terms of age, gender and the number of remaining teeth.

\section{References}

1. Embree MC, Iwaoka GM, Kong D, et al. Soft tissue ossification and condylar cartilage degeneration following TMJ disc perforation in a rabbit pilot study. Osteoarthritis Cartilage. 2015;23(4):629-639.

2. Cisewski SE, Zhang L, Kuo J, et al. The effects of oxygen level and glucose concentration on the metabolism of porcine TMJ disc cells. Osteoarthritis Cartilage. 2015;23(10):1790-1796.

3. Shi C, Wright GJ, Ex-Lubeskie CL, Bradshaw AD, Yao H. Relationship between anisotropic diffusion properties and tissue morphology in porcine TMJ disc. Osteoarthritis Cartilage. 2013;21(4):625-633.

4. Pandis N, Karpac J, Trevino R, Williams B. A radiographic study of condyle position at various depths of cut in dry skulls with axially corrected lateral tomograms. Am J Orthod Dentofac Orthop. 1991;100(2):116-122.

5. Katsavrias EG. Changes in articular eminence inclination during the craniofacial growth period. Angle Orthod. 2002;72(3):258-264.

6. White SC, Pharoah MJ. Oral Radiology: Principles and Interpretation. $7^{\text {th }}$ ed. St Louis, MO: Mosby; 2014:501,509.

7. Barghan S, Tetradis S, Mallya SM. Application of cone beam computed tomography for assessment of the temporomandibular joints. Aust Dent Assoc. 2012;57(Suppl 1):109-118.

8. White SC, Pharoah MJ. Oral Radiology: Principles and Interpretation. $6^{\text {th }}$ ed. St Louis, MO: Mosby; 2009:238.

9. Al-Ekrish A. A retrospective study of the prevalence and reliability of the diagnosis of soft tissue calcification of the temporomandibular joint in cone beam computed tomography images. King Saud Univer J Dent Sci. 2013;4(2):81-85.

10. de Boer EW, Dijkstra PU, Stegenga B, de Bont LG, Spijkervet FK. Value of cone-beam computed tomography in the process of diagnosis and management of disorders of the temporomandibular joint. Br J Oral Maxillofac Surg. 2014;52(3):241-246.

11. Siriwat $P$, Jarabak J. Malocclusion and facial morphology: Is there a relationship? An epidemiologic study. Angle Orthod. 1985;55(2):127-138.

12. Hegde S, Praveen BN, Ram Shetty S. Morphological and radiological variations of mandibular condyles in health and diseases: A systematic review. Dentistry. 2013;3(1):154.

13. Ejima K, Schulze D, Stipping A, Mastsumoto K, Rottke D, Honda K. Relationship between the thickness of the roof of glenoid fossa, condyle morphology and remaining teeth in asymptomatic European patients based on cone beam CT data sets. Dentomaxillofac Radiol. 2013;42(3):90929410.

14. Wood N, Goaz P. Differential Diagnosis of Oral and Maxillofacial Lesions. $5^{\text {th }}$ ed. St. Louis, MO: Mosby; 1996:393-412.

15. Atkinson WB, Bates RE. The effects of the angle of the articular eminence on anterior disk displacement. J Prosthet Dent. 1983;49(4):554-555.

16. Panmekiate S, Petersson A, Akerman S. Angulation and prominence of the posterior slope of the eminence of the temporomandibular joint in relation to disc position. Dentomaxillofac Radiol. 1991;20(4):205-208.

17. Isberg A, Westesson PL. Steepness of articular eminence and movement of the condyle and disk in asymptomatic temporomandibular joints. Oral Surg Oral Med Oral Pathol Oral Radiol Endod. 1998;86(2):152-157.

18. Jasinevicius TR, Pyle MA, Nelson S, Lalumandier JA, Kohrs KJ, Sawyer DR. Relationship of degenerative changes of the temporomandibular joint (TMJ) with the angle of eminentia. J Oral Rehabil. 2006;33(9):638-645.

19. Kerstens HC, Tuinzing DB, Golding RP, Van der Kwast WA. Inclination of the temporomandibular joint eminence and anterior disc displacement. Int J Oral Maxillofac Surg. 1989;18(4):228-232.
20. Sümbüllü MA, Cağlayan F, Akgül HM, Yilmaz AB. Radiological examination of the articular eminence morphology using cone beam CT. Dentomaxillofac Radiol. 2012;41(3):234-240.

21. Katsavrias HG. Morphology of the temporomandibular joint in subjects with class II division 2 malocclusions. Am J Orthod Dentofacial Orthop. 2006;129(4):470-478.

22. Zain-Alabdeen EH, Alsadhan RI. A comparative study of accuracy of detection of surface osseous changes in the temporomandibular joint using multidetector CT and cone beam CT. Dentomaxillofac Radiol. 2012;41(3):185-191.

23. İlgüy $D$, İlgüy $M$, Fişekçioğlu $E$, Dölekoğlu S, Ersan N. Articular eminence inclination, height, and condyle morphology on cone beam computed tomography. Sci World J. 2014;2014: ID:761714.

24. Sülün T, Cemgil T, Duc J-MP, Rammelsberg P, Jäger L, Gernet W. Morphology of the mandibular fossa and inclination of the articular eminence in patients with internal derangement and in symptom-free volunteers. Oral Surg Oral Med Oral Path Oral Radiol Endod. 2001;92(1):98-107.

25. Kurita $H$, Ohtsuka A, Kobayashi $H$, Kurashina K. Flattening of the articular eminence correlates with progressive internal derangement of the temporomandibular joint. Dentomaxillofac Radiol. 2000;29(5):277-279.

26. Gökalp $\mathrm{H}$, Türkkahraman $\mathrm{H}$, Bzeize N. Correlation between eminence steepness and condyle disc movement in temporomandibular joints with internal derangements on magnetic resonance imaging. Eur J Orthod. 2001;23(5):579-584.

27. Galnate G, Paesani D, Tallents RH, Hatala MA, Katzberg RW, Murphy W. Angle of the articular eminence in patients with temporomandibular joint dysfunction and asymptomatic voluteers. Oral Surg Oral Med Oral Pathol Oral Radiol Endod. 1995;80(2):242-249.

28. Jasinevicius TR, Pyle MA, Lalumandier JA, et al. Asymmetry of the articular eminence in dentate and partially edentulous populations. Cranio. 2006;24(2):85-94.

29. Kijima N, Honda K, Kuroki Y, Sakabe J, Ejima K, Nakajima I. Relationship between patient characteristics, mandibular head morphology and thickness of the roof of the glenoid fossa in symptomatic temporomandibular joints. Dentomaxillofac Radiol. 2007;36(5):277-281.

30. Tsuruta A, Yamada K, Hanada K, et al. Thickness of the roof of the glenoid fossa and condylar bone change: A CT study. Dentomaxillofac Radiol. 2003;32(4):217-221.

31. Maeda Y, Mori T, Maeda N, Tsutsumi S, Nokubi T, Okuno Y. Biomechanical simulation of the morphology change in the temporomandibular joint. Part 1: Factors influencing stress distribution. J Jap Soc Temporomand Joint. 1991;3(1):1-9.

32. Honda K, Larheim TA, Sano T, Hashimoto K, Shinoda K, Westesson PL. Thickening of the glenoid fossa in osteoarthritis of the temporomandibular joint: An autopsy study. Dentomaxillofac Radiol. 2001;30(1):10-13. 